\title{
Mothering in a Pandemic: Navigating Care Work, Intensive Motherhood, and COVID-19
}

\author{
Molly Wiant Cummins ${ }^{1}$ (D) Grace Ellen Brannon ${ }^{1}$ (D)
}

Accepted: 4 February 2022 / Published online: 3 March 2022

This is a U.S. government work and not under copyright protection in the U.S.; foreign copyright protection may apply 2022

\begin{abstract}
Even before COVID-19, women around the world performed more unpaid domestic labor, specifically unpaid care labor, than men. COVID-19 has only exacerbated the gender gap in this domestic labor. For Western women, especially mothers in the United States of America, the normative discourse of intensive motherhood and the gendered pressure inherent in the unrealistic standards set by the discourse have only increased the amount of unpaid domestic and care labor required of mothers. Using qualitative, in-depth interviews with 18 mothers during May-June 2020, this study examines privileged mothers' perceptions of what they did well in parenting both before and during the early part of the COVID-19 pandemic. The mothers' pragmatic adaptations during the pandemic posed challenges to the norms of intensive motherhood, as did emergent ideas about integrative mothering articulated before the pandemic's onset. We find that while COVID-19 has increased expectations on mothers, it has also provided a turning point wherein expectations can be changed, as the participants suggested. Implications for intensive motherhood scholars, mothers, and communication researchers are discussed, along with future research.
\end{abstract}

Keywords Intensive motherhood · COVID-19 - Gendered pressures · Qualitative methodology

The Organisation for Economic Co-ooperation and Development (OECD) explains unpaid care and domestic work as "non-market, unpaid work carried out in households (by women primarily, but also to varying degrees by girls, men and boys) which includes both direct care (of persons) and indirect care (such as cooking, cleaning, fetching water and fuel, etc.)" [47, para. 2]. As the OECD noted, most

Molly Wiant Cummins

molly.cummins@uta.edu

Grace Ellen Brannon

grace.brannon@uta.edu

1 Department of Communication, University of Texas Arlington, Arlington, TX, USA 
unpaid care work is performed by women. According to a 2018 International Labour Organization (ILO) report, women perform 76.2 percent of the total unpaid care work around the world, which is 3.2 times what men perform [33, p. 3]. This translates to an average of four hours and 25 min per day compared to men's one hour and 23 min of unpaid care work [33, p. 3].

Given these statistics, it comes as no surprise that the COVID-19 pandemic disproportionately affected women. In the United States of America (U.S.), nearly 2.4 million women have dropped out of the workforce since February 2020 [57] in part due to the sudden need for unpaid care work during lockdowns. For mothers, the pandemic has been especially difficult [49]. Cohen and Hsu [12] claimed that while most families have more stress because of COVID-19, mothers in heterosexual couples are spending $15 \mathrm{~h}$ more per week on education and household tasks, on average. Spurred by these statistics, Senator Tammy Duckworth wrote in Time in August 2020, "American moms are running on empty. Every morning, we wake up feeling guilty that we're not doing enough. Every night, we go to sleep terrified that we're failing" [22, para. 1-3]. Senator Duckworth named an experience so common that the New York Times created "The Primal Scream," a hotline where mothers can call in and share their frustrations in one-minute voicemails so they may see "all the messy, heartbreaking moments of everyday fear and chaos, and the rays of joy that can sometimes shine through" [28, para. 17] and know they are not alone.

Prior to COVID-19, mothers navigated a complex parenting terrain in the U.S., facing a lack of federal parenting policies (e.g., paid parental leave) and increasing demands of intensive motherhood [30], a normative discourse relegating mothers to the sole role of child-rearing. Mothers attempted to "have it all," to find a balance between work and family that rarely equalized and left them chasing unrealistic possibilities [26, 36, 59]. The added worries of the pandemic (e.g., full-time employment while navigating a child's remote schooling) have created a perfect storm where mothers are struggling like never before and will continue facing longterm gender inequality in the workplace and at home long after the pandemic subsides [65]. As O'Reilly argues, "[N]ormative motherhood discourses are rewritten in response to, and as a result of, significant cultural and economic change" [48, p. 44]. Given that COVID-19 has dramatically shifted how the world operates, it stands to reason that society is in a liminal space of possibility, ready to challenge motherhood discourses. Yet, the U.S. continues to rely on mothers to complete the extra labor to "bridge the gaps between cultural change and its effect on childrearing" [8, p. 40], treating unpaid care work performed by women as "if it were a costless renewable resource" [17, p. 685]. A year into the pandemic, we see that this pattern continues $[29,65]$, despite knowing that family policies such as paid maternity leave result in better health outcomes and may even help reduce social disparities [34].

We began this project intending to interview mothers about their perceptions of their own mothering. However, as our project began, the U.S. officially recognized COVID-19 as a national health emergency. Thus, we had the unique opportunity to interview mothers about their perceptions of mothering both before COVID-19 and in the early months of the U.S. lockdown. We asked mothers what they believed they were doing well as parents before COVID-19 and how that shifted as COVID19 became a daily reality in their families. We recognize that mothers' perceptions 
of their "good parenting" were already colored by the pervasive cultural discourse of intensive motherhood [30]. Yet, their answers also illuminated how the discourse might be shifting. Here, we show some of the ways privileged mothers are recognizing and individually challenging intensive motherhood. We begin by discussing the division of labor in unpaid care work, intensive motherhood, and how unpaid care work and intensive motherhood have both been affected by COVID-19. Then, we turn to the mothers' answers and reflections throughout the interviews. Finally, we offer implications of COVID-19 on intensive motherhood discourse as related to the lived experiences of the participants.

\section{Building a Foundation}

\section{Pre-COVID-19}

Twenty years ago, Bianchi et al. [6] explained that though the gap was less than it had been in previous years, women (in heterosexual, cohabitating relationships) still performed most of the unpaid domestic labor (e.g., housework). This has consistently been the case around the world [25, 33, 61]. Elson argued that gender equity gains stalled around 2014 [23], positing that the gender wage gap will not end until the unpaid care work gap is recognized and closed (see also [60]). Moreover, Cooke and Hook found that all working women "incurred some wage penalty" for routine housework, even as "the penalty lessened" for top wage-earners [15, p. 733] due to the volume argument which predicts that higher wage-earners spend less time doing housework and thus, "the wage penalty for housework decreases across women's wage distribution" [15, p. 722]. Yet only the highest-earning men "incurred significant wage penalties for routine housework on employment days" [15, p. 733], demonstrating "little variation in the housework penalty across men's wage distribution," per the volume argument [15, p. 722]. Thus, women are routinely penalized for engaging in the unpaid care work of the home.

Undoubtedly, the breakdown of who will perform what unpaid labor in the home is steeped in cultural gender norms and discourses. As these norms become sedimented over time, they begin to seem natural. It should come as no surprise that even when employed full-time, women do more of the unpaid domestic labor [19]. Further, men are more likely to arrange family time around paid work whereas women arrange paid work around family [19]. The result is that men can spend more time in paid work because of their lessened responsibility for housework [10] and/or spend more time engaging in leisure compared to women [35]. Perhaps surprisingly, the unpaid care work gap lessens in childcare; in the last few decades, both women and men have increased time spent on childcare [50]. Still, most unpaid care work is tied to what Milkie et al. referred to as gendered pressures, that, for women, "Performing a task expends the precious resource of time, but also may create feelings of responsibility, generate additional cognitive load, and be understood in terms of how it fits with what wives 'should' be doing with their time" [38, p. 171]. The gendered pressures Milkie et al. [38] described complement Western notions of intensive 
motherhood [30], specifically in the U.S. As a cultural discourse helping to shape the norms of "good" mothering, intensive motherhood underscores gendered ideas of who should perform unpaid care work.

\section{Intensive Motherhood}

In The Cultural Contradictions of Motherhood, Hays identified intensive motherhood as the prevailing discourse of what constitutes good mothering, explaining the normative discourse is "child-centered, expert-guided, emotionally absorbing, labor-intensive, and financially expensive" [30, p. 8, emphasis original]. Moreover, Hays said intensive motherhood persists because the discourse is what society believes children "need and deserve" [30, p. 21], as based on a White, privileged norm. Building on Hays's [30] work, Douglas and Michaels wrote about "the new momism" which is "a highly romanticized and yet demanding view of motherhood in which the standards for success are impossible to meet" [21, p. 4] and which they primarily discuss in relationship to mass media. Intensive motherhood has also been discussed as patriarchal motherhood [48], the motherhood mystique [42], total motherhood [64], and hegemonic mothering [46]. As O'Brien Hallstein summarized, intensive motherhood is "the proper ideology of contemporary intensive mothering that all women are disciplined into, across race and class lines, even if not all women actually practice it" [44, p. 143, emphasis original]. These discourses demonstrate that a "good mother" is one who spends considerable time, energy, and resources focused on her children.

Not every mother is the ideal standard for intensive motherhood, however. The ideal mother is White, middle-class, cisgender, heterosexual and ideally married [45]. Although it is not explicitly stated in the good mother ideal, mothers can assume this also means they should be able-bodied (without physical disabilities), deemed acceptable to reproduce (both in terms of race-read White-and intellectual ability), and an appropriate age (not too young and not too old). Those who are outside of the ideal can strive to meet intensive motherhood standards but will rarely, if ever, be considered good mothers as a result. As Green noted, "Despite many cultural contradictions and diverse parenting arrangements and practices, intensive mothering remains the normalised cultural and political standard by which motherhood, mothering and mothers are evaluated" [27, p. 198]. Intensive motherhood remains the hegemonic standard against which all mothers are judged.

Intensive motherhood creates unrealistic expectations for mothers, what O'Reilly calls "idealization" [48, p. 14]. The idealized version of good motherhood has resulted in "naturalization" [48, p. 14] as well in which mothers are assumed to be naturally maternal, that they will instinctively know how to mother [39]. Ennis posited the lack of support "from family, from government, from the workplace and from one another" has made motherhood an isolating experience for those who buy into this understanding of parenting [24, p. 8], what O'Reilly names as individualization [48]. This is underscored by intensive motherhood's connection to neoliberalism which places responsibility squarely on the individual and devalues the carework of mothering (by all genders) because the work is "outside the scope of market 
valuation" [43, p. 97]. The rise of intensive motherhood informed and shaped by neoliberalism creates a "perfect storm" for mothers who "must do far more work with far less resources" [48, p. 57]. Simply, without institutional support and/or policies that allow for family time, "mothers' employment makes it categorically impossible to fulfill the dictates of intensive mothering" [14, p. 3]. For Collins [13], the impossibility of fulfilling intensive motherhood dictates translates to increased guilt for mothers. When it comes to unpaid care work, the guilt may be magnified for privileged mothers who outsource their domestic labor to other women, further reinscribing Milkie et al.'s notion of gendered pressures [38] and leaving unpaid domestic labor devalued [41]. The gendered pressures, including guilt, only intensified in the wake of a global pandemic.

\section{Unpaid Domestic Labor and COVID-19}

Unsurprisingly, given what the gendered breakdown of unpaid care work was prior to the pandemic, COVID-19 increased the pressure and reliance on women to continue to perform that labor. Collins et al. [14] argued that although men and women equally perceive domestic tasks that need to be completed, men are less likely to complete the tasks, leaving them to women partners. Further, Collins et al. reported that mothers "scaled back their work hours by about 5 per cent" while fathers' work hours remained stable between March and April 2020 [14, p. 102], showing that more mothers are reducing work responsibilities to meet domestic labor responsibilities with a troubling effect (i.e., a decline) on women's labor force participation [1]. Specifically, "the loss of full-time nonparental childcare was associated with an increased risk of job loss for mothers," who are "more likely to be employed when they have access to childcare options" [51, p. 527]. Managing children's athome education only added to the pressures mothers faced, with U.S. mothers facing "greater financial worry and emotional strain" related to their employment status and unpaid domestic labor during the early days of the pandemic [54, p. 2]. The increased employment worries spiral out to significant relationships as well, as Waddell and colleagues showed: Using surveys both before and during COVID-19, the researchers found that when women were saddled with more of the unpaid domestic labor, they were "more likely to experience increased relationship problems and dissatisfaction" [62, p. 1778]. When women attempt to reconcile the competing discourses of what constitutes a "good" mother and a "good" worker, they face increased pressure and guilt at not fulfilling either [63].

Given the prevalence of unpaid domestic labor performed by women both prior to and increased by COVID-19, the gendered pressures women, especially mothers, feel has been exacerbated by the pandemic. Afterall, "Crises can starkly expose longstanding and systemic social problems, and this has been the case with COVID19 and gendered divisions of labor" [18, p. 320]. Sarker agreed, saying, "Women in times of crisis are always vulnerable and more affected than men, and the coronavirus pandemic is no exception" [55, p. 597]. In our study, we contribute to the literature by interviewing mothers about their perceptions of mothering both before and during the early days of the COVID-19 lockdown in the U.S. These mothers 
described feeling increased pressure to perform good mothering, both informed by intensive motherhood standards and due to the influx of persistent unpaid care work during lockdowns, including children's at-home education. These interviews highlight ways privileged mothers in the U.S. may slowly be shifting the dictates of intensive motherhood toward more humanizing discourse, using the abrupt social change of COVID-19 as a necessary turning point for change. Next, we discuss our methods and participants before turning to participant narratives.

\section{Methods}

As mentioned above, we initially conceived our project to explore mothers' perceptions of their mothering, focusing on what they did well, with what they struggled, and how they compared themselves to others. Our initial project focused on mothers' perceptions of their mothering, including their perceptions of others' parenting and their own parents' parenting to see how mothers distinguished their styles from those around them. We received Institutional Review Board (IRB) approval as COVID-19 became a recognized health emergency in the U.S. As a result, our interview questions necessarily shifted. There was no way we could ask mothers to focus on their parenting without answers being overshadowed by the raging pandemic creating chaos in mothers' (everyone's) lives. Thus, our project as reported here focused on mothers' pragmatic adaptations and associated gendered pressures [38] both before and during COVID-19.

\section{Participants}

After obtaining IRB approval, we posted recruitment calls in several private Facebook groups specifically aimed at mothers, allowing us a diverse (e.g., age, race, ethnicity, and occupation) subject pool from geographically diverse areas in the U.S. Both Facebook groups have members living across the U.S. and are not (solely) local to us. This gave us access to 18 mothers over the age of 18 from across the United States. There were no exclusion criteria; interested participants needed to be at least 18, speak English, and identify as mothers to participate. We fielded responses from interested participants, then had two or three interviews through snowball sampling before reaching saturation in our data [16]. Recent research on motherhood studies uses similar numbers (e.g., [58]: 15 participants). Each participant self-reported their gender identity, and all 18 identified as cisgender women married to men. The participants' ages were primarily in the 30s-40s range, for those who chose to report their ages. Participants reported having between one and four children in total, with most of the children being five years old or younger; the children's ages at time of interview ranged from 7 weeks old (born during the COVID-19 pandemic) to elementary school. Many mothers reported facing unique parenting situations ranging from being mothers of multiples (e.g., twins) to children with various diagnoses, such as time spent in the Neonatal Intensive Care Unit (NICU) to ADHD or generalized anxiety disorder (GAD). Levels of education varied, with some of the mothers being highly educated (at least a Master's degree). Most of the mothers were White 
( $n=16)$ with careers outside of the home $(n=16)$. While the homogeneity of much of the participant pool is a limitation we recognize, it also allowed us to recruit participants we already had access to via Facebook mothering groups to which we each belong. Further, intensive motherhood discourse upholds a homogenous ideal [48]; thus, our participant pool represented candidates most likely already rhetorically situated as good in intensive motherhood. Moreover, with the new public health emergency, many mothers were still in survival mode as they navigated the local stay-at-home orders, school closings, and other major life shifts. Those mothers who might have been facing extreme situations (e.g., job loss, home loss, food insecurities, and/or domestic abuse) were not the individuals signing up to be interviewed at that point in time. The threat of the pandemic meant that those privileged mothers-affluent women in relatively stable domestic situations-who had the emotional capacity, time, and access to resources to be interviewed were the people who responded to our call. Even reaching out to our personal networks or further recruiting through snowball sampling did not allow for a more diverse participant pool. Future research should continue examining these unique perspectives.

\section{Procedures}

We designed the initial semi-structured interview guide to elicit the mothers' stories about their perceptions of successes and struggles as mothers using open-ended questions asking for examples (Appendix A). While we thought these questions would allow us to better understand how mothers perceive their own mothering, one of our participants highlighted how our framing of the questions was problematic. The participant explained that our questions asked mothers to compare themselves to others, an individualizing move reminiscent of intensive motherhood [48], rather than think about motherhood as a collective and politically efficacious space. We did not define success or struggle for participants; rather, we let them explain their answers based on their own perceptions. Yet, in the same way that resilience is seen to have moral overtones [5], so, too, might success carry particular connotations in the way we framed our questions. Even as we investigated intensive motherhood, we reproduced it through the framing of our interview questions. We therefore recognize that troubling our own questions or the definitions of terms in those questions is an important lesson learned from this project [3].

Between May and June 2020, we first asked participants to verbally acknowledge informed consent and we gave participants the opportunity to ask and have any questions answered about the project. Afterwards, we asked a brief demographic questionnaire, and began audio recording. We conducted eighteen individual interviews, lasting between 22-54 min, for a total of almost $11 \mathrm{~h}$ of recorded data. Once collected, the interviews were transcribed near verbatim, excluding filler words as they did not alter meanings. This process resulted in about 154 transcribed pages of single-spaced typed data, with about 60 pages of handwritten and typed notes made during the interviews and data analysis procedures. After transcribing the interviews, we each coded the interviews individually looking for common themes across the data through grounded theory $[2,11]$. We identified emergent themes through thematic analysis and resolved 
any differences via discussion. Next, we used open coding to identify the major areas of information, many of which aligned with our interview protocol. We then used axial coding to note our categories and subcategories before we used selective coding to highlight exemplars of our themes [20]. We reached theoretical saturation [16] after rereading the transcripts and finding no new or emergent themes. We report participant-chosen pseudonyms throughout the results section.

\section{Mothers' Perceptions}

In this section, we analyze the words of participants as they describe their adaptations both pre-COVID-19 and during COVID-19. Others [56, 62] have used surveys to compare before and during-the-pandemic results, but, to our knowledge at the time of writing, this is the first study using qualitative interviews. Again, we recognize that phrasing our interview questions in the binary of success versus struggle disallowed participants to more holistically consider or detail how they perceived their own mothering. As a result, participant answers bled across the false lines we had constructed. Moreover, given that our interviews were during the early part of the pandemic, participants were certainly in flux as they answered our questions. As such, many participants demonstrated how these themes intersected; asking them to answer about parenting wins was often interspersed with the ways they felt they were struggling and vice versa. Similarly, the adaptations before COVID-19 often bled into answers for how mothers were adapting during the pandemic. Although we found some similarities across participants' answers, the definitions of good mothering are unique to each individual. The similarities, however, demonstrate some of the ways mothers' perceptions have been informed by intensive motherhood. Because they all live and mother under the same normative discourse, their definitions are marked by commonalities.

Perhaps unsurprisingly, the mothers with the most access to resources (e.g., high income; dual-income homes; childcare throughout the pandemic) were the mothers who seemed most able to name their adaptations as positive. Other participants struggled to name ways they saw felt they were doing well in their mothering. This was particularly the case with Tasha, a White military spouse with two children under four, who seemed to be truly struggling throughout the interview. She remarked that she was "just waiting for this period of life to be over" when considering the pandemic. Speaking with participants like Tasha illuminated how intensive motherhood norms might bog mothers down, might create shame and guilt spirals (e.g., [13, 63]) where mothers feel like they are floundering. We offer first the integrative mothering of pre-COVID-19 to create a baseline of what the mothers considered "normal" life before the pandemic, showing subtle ways some participants were already resistive to intensive motherhood norms and the gendered pressures they felt as paid labor and unpaid labor collapsed into one space.

\section{Integrative Mothering}

At a fundamental level, many participants saw good mothering in their ability to meet their children's basic needs of food, shelter, clothing, and cleanliness. For some 
mothers, this baseline normalcy felt like a "low bar," such as for Suzanna, a White mother who works in IT security with two daughters under the age of 10. Suzanna explained good mothering as her children not feeling neglected even as she works a full-time job. Suzanna's concern emphasized mothers' individual definitions of good mothering which are highlighted in their answers even if another participant might judge that answer as insufficient mothering. Suzanna's comment also highlights a resistance to intensive motherhood norms, however. That good mothering for Suzanna is something she understands might be a "low bar" for someone else means she is not as invested in living up to unrealistic standards to feel like a good mother.

Arguably, meeting basic needs is a marker of good motherhood, intensive or otherwise. Yet, importantly, some mothers made mention of good mothering that run counter to intensive motherhood. Several participants explicitly marked the importance of their marriage/partnership as foundational to good parenting, naming equality or teamwork in parenting as vital. Trish explains that she and her husband are "intentional" about their marriage, specifically naming this intentionality as part of her good mothering, so their children will be raised in an environment of "security." Sparrow, a White, stay-at-home mother to three daughters five and under (the youngest born during COVID-19), explained that it is important that she and her husband are equals in their relationship. She feels they have been fruitful in that endeavor when their children call them out in moments where they believe something is unfair for one parent or the other. Intensive motherhood compels mothers to be the primary parent intensively focused on childcare; for mothers to emphasize the importance of their partners and/or relationships in parenting is a shift away from the normative discourse.

Likewise, a few mothers highlighted how important their careers outside the family were to their identity and perceptions of good parenting. For Lillian L, a White mother to a 6-year-old son, good mothering is modeling that she is a leader and a career woman to her child. Carol, a White marketing professional mother to three daughters between the ages of 3 and 8 , too, feels like a good mother when she hears her daughters mention they want to be moms in addition to careers; it makes her feel that she "must be exhibiting something that they see as a positive." One of the strongest examples came from Kate, a White, professor with a Ph.D., and mother to a four-year-old son and a two-month-old son, who told a story about her motherin-law telling her child, "Mom has to go to work so that you can have all these nice things." Kate corrected her mother-in-law, explaining that they would still have nice things if Mom stayed home, but that Mom goes to work because she loves what she does and wants to help other people love thinking and writing. Kate says it was important that her child understand that work was not in service of the child (e.g., to pay bills), but in service of herself because she enjoys her job. Moreover, Kate believes that when she is at work, she is giving her children opportunities to be loved by other people, to engage in education and friendship. She is a mother all the time when she approaches it this way; her mothering does not stop when she is not physically present with her children. Kate's view of mothering allows her to create an identity somewhere between worker and mother, drawing upon the importance of each of these personas in her overall identity. In this way, mothers enjoying their 
careers outside the home becomes a challenge to intensive motherhood. They are not expressing only guilt or fear of failing at mothering; these mothers see their mothering as tied directly to their lives outside of their children.

Participants' abilities to navigate the delicate balance of work and home was not separate from intensive motherhood and its inherent gendered pressures. The idea of "leaning in" so that mothers can "have it all" is a neoliberal feminist ideal [53]. Having it all, as Kornfield explained is "implicitly defined as a fulfilling career and a fulfilling home life, and a fulfilling home life is constituted by a stable, passionate, heterosexual romance, a close relationship with happy and healthy children, and a well-groomed middle-class (or above) home" [36, p. 181]. In other words, intensive motherhood, informed by neoliberal feminism, has simply changed the standards of what working mothers should strive toward to be "successful." Indeed, the working mother conception of good mother can "exacerbate the tensions" between work and home, adding to mothers' feelings of failure and guilt [7, para. 48]. As Buzzanell and colleagues explained, the image of the "good working mother" is fragile and those mothers who engage in this construction view their careers, regardless of their enjoyment of the work, as benefitting the family rather than themselves [9, p. 276]. Buzzanell et al. continued, saying the participants in their study framed paid work as better for the whole family "because they [the participants] are better mothers when they are able to go to work..." [9, p. 276]. The participants in our study understood their careers as making them better mothers, but also, as Kate's reframing of her mother-in-law's comments demonstrated, participants do not always engage in a compartmentalization of home and work life; rather, they see the two as combined and informing one another. Instead, these mothers resisted intensive motherhood as they see the necessity of their partners in equal child-raising and/or choose to work outside the home, even if that choice is neoliberally informed. This marks a potential shift in the normative discourse of intensive motherhood. If mothers see the power of viewing their mothering as integrative, as capable of subsuming mothering dialectics (such as working mother or stay-at-home mother), they present a powerful challenge to intensive motherhood, shifting the gendered pressure of who should be responsible for the unpaid care work. Next, we discuss how mothers' perceptions of their adaptations during COVID-19 may present challenges to intensive motherhood norms.

\section{Triage Parenting and Adaptation}

The dramatic shift of COVID-19 emphasized that struggles are felt more acutely than positive parenting moments, which often require reflection after the fact [4]. Understandably, listening for participants' adaptations during a crisis was sometimes a difficult endeavor. For example, at least five mothers mentioned some version of just getting through the day as good mothering during COVID-19, indicating their understanding of good mothering parameters having drastically changed. For example, Gail, a White working mother of two sons under age 9, said she did not think the prevailing feeling during the pandemic was good mothering, but that if she looked objectively rather than emotionally, her children are "healthy and safe and 
fed," which felt like good mothering. One participant, Martina, a part-time nurse, and mother to a 9-year-old son and 4-year-old twin boys, named this meeting of basic needs as "triage" parenting, an important adaptation in the immediate aftermath of the pandemic. This idea of triage parenting became a common chord we heard from participants. For example, Carol said, "I sort of feel like I'm a C + parent on the best of days, and that's sort of what I'm gunning for...." Some days, they suggested, surviving alone felt like a monumental accomplishment, like Mandy, a White mother to a 3-year-old son and 3-month-old twin boys (born during the pandemic), who felt that being able to get through a day without herself crying was a big accomplishment. The recognition that parameters have shifted, that triage parenting through a trauma is good mothering, is primary to changing the norms of intensive motherhood. Carol's rating of her parenting as $\mathrm{C}+$ indicates that she knows there is a standard she is supposed to meet (what she might rank A+parenting), yet she is content with the $\mathrm{C}+$ and says that is her goal. She does not seek to live up to the unrealistic standards of intensive motherhood. Instead, she understands how much she can give as a mother and striving for that is enough for her. Although the participants noted that these moments felt small, they are nonetheless potential challenges to intensive motherhood and the gendered pressure to shoulder this work alone.

In addition to triage parenting, Gail also said that good mothering during COVID19 meant trying to have honest, age-appropriate conversations with her children about the pandemic. Other mothers echoed this, finding good mothering in allowing space for their children and themselves to process emotions and/or ask questions about the pandemic. Beyond that, connecting with their partner or spouse was also important for many participants, particularly for Carol, who described her and her partner's roles as extending to "cruise director, homesteader, homeschooler..." saying that the struggles related to the pandemic created strain, because "at the end of the night we're just toast," meaning they were so exhausted by the end of the day they did not have the energy to make time for one another. She followed up her description saying that she sent him a text, saying "I miss you," implying that those simple moments of intentional connection with significant others beyond their children were important. Carol echoes the intentionality Trish used above to demonstrate the importance of relationships with others outside of the child/ren, especially a spouse. Although potentially coopted by intensive motherhood discourse focused on heteronormative and/or nuclear family relationships, highlighting the importance of identity outside of the mother label represents a small resistance to intensive motherhood demands.

The most common way mothers indicated they felt they were engaging in good mothering through COVID-19, however, was adaptation. Mothers were (and are) taking what they have been given and trying to create something positive. Many mothers mentioned carving out more time to spend with their children, making more time for connection with them. Leslie, a lawyer, and mother to an 8-year-old daughter and a 4-year-old son, noted that working from home, for her, means there was more time to see her children during the day, to help make their lunches as a point of connection. Most mothers also talked about finding a new routine amidst the chaos and/or relaxing the old (pre-COVID-19) routine to make life work. Lillian L engaged in good mothering during COVID-19 by trying not to put too much 
pressure on anybody, relaxing the routine to find a balance between coping and getting "to their work." Jennifer, who holds a Master's degree, and is a White mother to a 3-year-old daughter, said her main adaptation after COVID-19 has been working hard to maintain the same routine they had before the pandemic so from her daughter's perspective, not much has changed except that they are home more. Ultimately, this adaptation to how life works is the major parenting win for mothers during COVID-19. Of note here are at least three participants (Anne, Carol, and Leslie) who explicitly mention that a major driver of positive parenting moments during the pandemic is not having to be the primary parent on everything - a powerful resistant narrative to the gendered pressure of intensive motherhood as parents navigate this new experience. Adaptation from these participants demonstrates their understanding that life shifted, and they had to shift along with it. Through that shift, participants could further explore what parts of parenting felt rewarding to them rather than what normative discourse dictates. By exploring their own positive parenting moments, participants resisted intensive motherhood in minute ways, allowing them to see how parenting could be done differently.

\section{Implications}

This study is unique in that it is one of the first to examine mothers' own perceptions on mothering during the early days of the COVID-19 pandemic in the U.S. That mothers were able to resist intensive motherhood norms during the COVID-19 pandemic is no small feat. It is, however, indicative of the way mothers continually adapt to the situations they face in order to keep moving forward, as previous research also shows [59]. This is not to say that all privileged mothers have similar stories or resistive moments such as changing the standard of what they consider good parenting to something like triage parenting like the mothers in this study; these participants do not represent a universal perspective. That the mothers in this study were able to find these moments of resistance is certainly related to their intersectionally privileged identities, which affects how current and future discourses may be challenged [40]. Although participants were not claiming to resist intensive motherhood explicitly, their answers demonstrate the ubiquitous nature of intensive motherhood, how mothers have internalized those standards [32], and how they may be pushing the discourse to shift.

To some degree, that mothers can find positive parenting moments in attempting to balance their work lives and home lives and/or their own needs and their children's needs amidst a pandemic is, in itself, resistant to intensive motherhood. Mothers are not focusing solely on their children, searching out expensive, expert guidance on how to move through COVID-19. Instead, mothers are making life work with what they have, learning to relax old routines to establish new ones and creating a new balance. This novel way of parenting challenges intensive motherhood, perhaps creating a shift in how the normative discourse demands unpaid care work moving forward as mothers navigate this liminal space. Since previous research shows that intensive motherhood ideologies have negative psychological effects on 
women, including decreased parental well-being, these are important areas of focus [52].

Even as mothers are challenging and shifting intensive motherhood, they are continually surrounded by the norms established by it [32]. The gendered pressure of extra parenting still primarily falls to mothers, a position that is "not sustainable" as one participant (Gail) put it. The expectations intensive motherhood requires of mothers, especially during a pandemic is not only exhausting; it is impossible. Rather than actively work to change or dismantle the existing inequitable policies that do not support families, intensive motherhood discourse places blame on mothers who do not live up to intensive expectations. Mothers are stronger collectively, but intensive motherhood expectations and individualization almost guarantee that mothers will not have the emotional capacity, time, and/or energy to push for greater change. In the end, this is how intensive motherhood reifies its hegemonic hold over mothers: continue to demand more with fewer resources until there is nothing left to give outside of the strict confines of the discourse [48]. Although mothers in our study have found ways to shift the standards of intensive motherhood amidst a pandemic, however minimal, it is mothers in general who are facing the extra responsibilities to thrive and mothers of color or non-binary and/or trans mothers who bear the brunt of the pandemic costs-economically and socially. This is further exacerbated by the blurring of lines between work and home during the COVID-19 pandemic.

Although it is a firmly entrenched discourse, intensive motherhood is, nonetheless, culturally and rhetorically constructed. As a construct, intensive motherhood recenters White, privileged mothers as the only acceptable model for parenting through insidious depictions in media and everyday conversations about how parenting should happen. Regardless of how aware privileged mothers are of intensive motherhood by name, they are aware of some invisible standard which works to individualize their experiences and individuate them from other mothers. Because intensive motherhood is a construct, however, it is "neither natural nor inevitable" but can be "challenged and changed" [48, p. 16]. Challenging intensive motherhood is accomplished by creating resistant narratives, small fissures in the façade of the discourse that can grow and spread. As Olson and Simon [46] discuss in relationship to breastfeeding discourse, challenging intensive motherhood is about creating a discursive space where choices are recognized and valued. This is not to say there should not be some standard of "good" mothering, but that the current hegemonic standards are unrealistic, damaging to families, and ignorant of or resistant to ways of mothering outside of this norm. Thus, to change the gendered pressures and the discourse of intensive motherhood under which all mothers are judged, society must look outside the intensive motherhood ideal to find ideas. Moreover, privileged mothers must follow the lead of and amplify the messages of parents of color, non-binary/ queer parents, and non-Western parents to change intensive motherhood. Collective work across intersectional identities and positionalities is the only hope of dismantling a system designed to reinforce a feeling of failure in mothers aimed at disciplining them back into the fold of intensive motherhood norms. 


\section{Limitations and Future Directions}

We had several limitations. First, participant demographics were fairly homogenous. Participants were primarily cisgender women married to men, with the majority being White and having careers outside of the home. Yet, research details intensive motherhood as most often tied to White mothers' feelings of motherhood as oppressive [48] hence our focus on their experiences. Further, since the pandemic is disproportionately affecting Black, Indigenous, and Hispanic populations, particularly through home and food insecurities, the experiences these women may have reported would likely have changed the results given that mothers of color often view motherhood through a different lens [31]. Relatedly, given the timing of the pandemic, alongside the authors' own mothering and work balances and the fact that both authors are White or White-presenting, it would have been a challenge to earn participant trust during this global event. Still, because White mothers often reinscribe intensive motherhood [42], it is imperative that they (we) are also part of the frontlines of changing the discourse by listening to and learning from mothers of color. Therefore, future research should examine the lived experiences of marginalized populations, as the ways they push back against intensive motherhood may be different than that of our study's population. Specifically, looking at mothering resilience not only during the COVID-19 pandemic, but amidst racism, attacks on Asian American/Pacific Islanders because of the pandemic, and even the routine separation of families at the U.S. southern border would be powerful.

Second, we conducted all interviews in the study via telephone. We used this modality to encourage greater participation as many people are facing Zoom/videochatting fatigue, as well as Internet connectivity issues. There were some occasions when having facial expressions to connect with the comments or discussion would have been helpful for data interpretation, so the addition of these nonverbal cues would have been helpful. Because we recommend that future research focus on marginalized mothers and their perspectives of intensive mothering, and Internet access may be an issue, we do feel that telephone interviews were a good substitute as faceto-face meetings would be a public health issue.

Third, research should continue to examine perceptions of mothers as the COVID-19 pandemic continues. Current research shows that COVID-19 effects are worsening preexisting gender inequalities, with negative long-term implications for women's employment regarding exiting the workforce and decreased working hours [37]. Further, women are primarily the frontline workers (e.g., healthcare) during the pandemic, and are the primary caregivers to children facing school and daycare closures [14] thereby increasing a family's (the mother's) domestic duties. Given the numbers of women leaving the workforce, especially to stay at home and care for children, it is vital that research continues to examine how these mothers' perceptions of motherhood have shifted. It is important to investigate long-term effects on each of these issues, but essential to examine them from the perceptions of the mothers themselves, particularly for health-related and social services research. Moreover, conducting follow-up interviews or creating a longitudinal study to investigate how mothering perceptions change over time would be important next steps for future research. 


\section{Conclusion}

In this study, we interviewed 18 mothers who primarily fit the intensive motherhood ideal about their perceptions of what they did well as mothers both before COVID-19 and during the pandemic. Although the experience of mothering is individualized through intensive motherhood, we found that mothers' perceptions of good mothering typically revolved around finding balance in their lives. The mothers in our study demonstrated through their responses the subtle ways they push back on the expectations they feel regarding intensive motherhood and its inherent gendered pressures, and we argue that their challenges to the discourse are shifting the norms of how it operates. That mothers can still find adaptation in the face of COVID-19, regardless of how difficult it may feel, is an important step to better understanding how intensive motherhood may be undermined. There is no doubt COVID-19 has drastically changed how mothers experience life and perceive their mothering abilities and associated unpaid care work; this break in the system creates space for mothers to collectively work toward dismantling a system that ultimately hurts all families. If normative motherhood discourses are rewritten in a time of change, then now is the time to change the discourse into more inclusive and humane expectations of all genders. Now is the time to work toward better ways of recognizing, understanding, and incorporating a variety of parenting techniques from the lay parent toward more gender equity in the unpaid care work sphere. Now is the time to create a supportive system for all.

\section{Appendix A}

1. Tell me about your family (age, race, job if applicable, marital status, number of kids, ages, special needs, unique situations, part of mommy groups).

2. In what ways do you feel you are succeeding as a mom?

3. In what ways do you feel you are succeeding as a mom during COVID-19?

4. In what ways do you feel you are struggling as a mom?

5. In what ways do you feel you are struggling as a mom during COVID-19?

6. In what ways do you compare your parenting experiences with other moms?

Would you share an example?

7. In what ways do you find yourself downplaying your parenting experiences?

8. How has the unique situation of ___ affected how you see yourself as a mom?

9. How does your parenting affect your family?

10. Can you talk more about how your parents' parenting has influenced yours?

11. How would you describe your parenting style?

12. How would you compare your parenting style to others?

13. Is there anything else you'd like to add about succeeding or struggling as a mom or what it means to be a mom? 
Author Contributions All authors contributed to the study conception, design, and reporting. Material preparation, data collection, and analysis were performed by Molly Wiant Cummins and Grace Ellen Brannon. The first draft of the manuscript was written by Molly Wiant Cummins, and all authors commented on previous versions of the manuscript. All authors read and approved the final manuscript.

\section{Declarations}

Conflict of interest The authors declare no conflicts of interest for this manuscript. No funding was received for conducting this study.

Ethical Approval We received ethical approval from the Institutional Review Board of the University of Texas at Arlington. The procedures in our study adhere to the Declaration of Helsinki tenets.

Consent to Participate We obtained informed consent from each participant included in the study.

\section{References}

1. Aaronson, D., Hu, L., \& Rajan, A. (2021). Did Covid-19 disproportionately affect mothers' labor market activity? Chicago Fed Letter Essays on Issues. https://doi.org/10.21033/cfl-2021-450

2. Aldiabat, K. M., \& Le Navenec, C. (2011). Philosophical roots of classical grounded theory: Its foundations in symbolic interactionism. The Qualitative Report, 16(4), 1063-1080.

3. Wiant Cummins, M., \& Brannon, G. E. (2022). Implicating ourselves through our research: A duoethnography of researcher reflexivity. Journal of Contemporary Ethnography, 51(1), 85-102. https://doi.org/10.1177/08912416211021898

4. Wiant Cummins, M., \& Brannon, G. E. (2021). The balancing act is magnified: U.S. mothers' struggles amidst a pandemic. In A. O'Reilly \& F. J. Green (Eds.), Mothers, mothering, and COVID-19: Dispatches from a pandemic (pp. 211-220). Demeter Press.

5. Baraitser, L., \& Noack, A. (2007). Mother courage: Reflections on maternal resilience. British Journal of Psychotherapy, 23(2), 171-188. https://doi.org/10.1111/j.1752-0118.2007.00016.x

6. Bianchi, S. M., Milkie, M. A., Sayer, L. C., \& Robinson, J. P. (2000). Is anyone doing the housework? Trends in the gender division of household labor. Social Forces, 79(1), 191-228. https://doi. org/10.2307/2675569

7. Blithe, S. J. (2015). Mobile working mothers and the simultaneous shift. The Electronic Journal of Communication/La Revue Électronique de Communication, 25(1 \& 2). http://www.cios.org/ejcpu blic/025/1/025104.html

8. Brown, S. (2014). Intensive mothering as an adaptive response to our cultural environment. In L. R. Ennis (Ed.), Intensive mothering: The cultural contradictions of modern motherhood (pp. 27-46). Demeter Press.

9. Buzzanell, P. M., Meisenbach, R., Remke, R., Liu, M., Bowers, V., \& Conn, C. (2005). The good working mother: Managerial women's sensemaking and feelings about work-family issues. Communication Studies, 56(3), 261-285. https://doi.org/10.1080/10510970500181389

10. Carlson, D. L. (2021). Time availability: Assessing causal ordering in the performance of paid labor and unpaid housework. Journal of Comparative Family Studies, 52(2), 180-205. https://doi.org/10. 3138/jcfs-52-2-003

11. Charmaz, K. (2006). Constructing grounded theory: A practical guide through qualitative analysis. Sage.

12. Cohen, P. \& Hsu, T. (2020, June 3). Pandemic could scar a generation of working mothers. The New York Times. https://www.nytimes.com/2020/06/03/business/economy/coronavirus-working-women. html

13. Collins, C. (2021). Is maternal guilt a cross-national experience? Qualitative Sociology, 44, 1-29. https://doi.org/10.1007/s11133-020-09451-2 
14. Collins, C., Landivar, L. C., Ruppanner, L., \& Scarborough, W. J. (2021). COVID-19 and the gender gap in work hours. Gender, Work \& Organization, 28(S1), 101-112. https://doi.org/10.1111/gwao. 12506

15. Cooke, L. P., \& Hook, J. L. (2018). Productivity or gender? The impact of domestic tasks across the wage distribution. Journal of Marriage and Family, 80, 721-736. https://doi.org/10.1111/jomf. 12467

16. Corbin, J., \& Strauss, A. (2008). Basics of qualitative research: Techniques and procedures for developing grounded theory (3rd ed.). London: Sage.

17. Craig, L. (2020). Coronavirus, domestic labour and care: Gendered roles locked down. Journal of Sociology, 56(4), 684-692. https://doi.org/10.1177/1440783320942413

18. Craig, L., \& Churchill, B. (2021). Working and caring at home: Gender differences in the effects of COVID-19 on paid and unpaid labor in Australia. Feminist Economics, 27(1-2), 310-326. https:// doi.org/10.1080/13545701.2020.1831039

19. Craig, L., \& van Tienoven, T. P. (2021). Gendered shares of the family rush hour in fulltime dual earner families. A cross national comparison. Social Indicators Research, 153, 385-405. https://doi. org/10.1007/s11205-020-02489-3

20. Creswell, J. W. (2007). Qualitative inquiry and research design: Choosing among five approaches (2nd ed.). Sage.

21. Douglas, S. J., \& Michaels, M. W. (2004). The mommy myth: The idealization of motherhood and how it has undermined all women. Free Press.

22. Duckworth, T. (2020, August 1). Sen. Tammy Duckworth: America's moms are running empty. We need to do more to support them. Time. https://time.com/5874524/tammy-duckworth-americasmoms-running-on-empty/

23. Elson, D. (2017). Recognize, reduce, and redistribute unpaid care work: How to close the gender gap. New Labor Forum, 26(2), 52-61. https://doi.org/10.1177/1095796017700135

24. Ennis, L. R. (2014). Intensive mothering: Revisiting the issue today. In L. R. Ennis (Ed.), Intensive mothering: The cultural contradictions of modern motherhood (pp. 1-23). Demeter Press.

25. Ferrant, G., Pesando, L. M., \& Nowacka, K. (2014). Unpaid care work: The missing link in the analysis of gender gaps in labour outcomes. OECD Development Centre. https://www.oecd.org/dev/ development-gender/Unpaid_care_work.pdf

26. Gilbert, J., \& Von Wallmenich, L. (2014). When words fail us: Mother time, relational attention, and the rhetorics of focus and balance. Women's Studies in Communication, 37(1), 66-89. https://doi. org/10.1080/07491409.2013.867915

27. Green, F. J. (2015). Re-conceptualising motherhood: Reaching back to move forward. Journal of Family Studies, 21(3), 196-207. https://doi.org/10.1080/13229400.2015.1086666

28. Grose, J. (2021, February 4). America's mothers are in crisis: Is anyone listening to them? The New York Times. https://www.nytimes.com/2021/02/04/parenting/working-moms-mental-health-coron avirus.html

29. Gross, T. (2021, February 18). Almost a year into the pandemic, working moms feel "forgotten," journalist says. NPR. https://www.npr.org/2021/02/18/968930085/almost-a-year-into-the-pandemicworking-moms-feel-forgotten-journalist-says?fbclid=IwAR3yWRRjuwtVfJKL5aKaQZJzA46A lpd_DDoujGLMcqB6QDZJr-v-bQune38

30. Hays, S. (1996). The cultural contradictions of motherhood. Yale University Press.

31. hooks, b. (2015). Feminist theory: From margin to center. Routledge.

32. Huisman, K., \& Joy, E. (2014). The cultural contradictions of motherhood revisited: Continuities and changes. In L. R. Ennis (Ed.), Intensive mothering: The cultural contradictions of modern motherhood (pp. 86-103). Demeter Press.

33. International Labour Organization (ILO). (2018). Care work and care jobs: For the future of decent work. https://www.ilo.org/wcmsp5/groups/public/---dgreports/---dcomm/---publ/documents/publi cation/wcms_633135.pdf

34. Jou, J., Kozhimannil, K. B., Abraham, J. M., Blewett, L. A., \& McGovern, P. M. (2018). Paid maternity leave in the United States: Associations with maternal and infant health. Maternal Child Health Journal, 22, 216-225. https://doi.org/10.1007/s10995-017-2393-x

35. Kamp Dush, C. M., Yavorsky, J. E., \& Schoppe-Sullivan, S. J. (2018). What are men doing while women perform extra unpaid labor? Leisure and specialization at the transitions to parenthood. Sex Roles, 78, 715-730. https://doi.org/10.1007/s11199-017-0841-0 
36. Kornfield, S. (2014). Pregnant discourse: "Having it all" while domestic and potentially disabled. Women's Studies in Communication, 37(2), 181-201. https://doi.org/10.1080/07491409.2014. 911233

37. Landivar, L. C., Ruppanner, L., Scarborough, W. J., \& Collins, C. (2020). Early signs indicate that COVID-19 is exacerbating gender inequality in the labor force. Socius: Sociological Research for a Dynamic World, 6, 1-3. https://doi.org/10.1177/2378023120947997

38. Milkie, M. A., Wray, D., \& Boeckmann, I. (2021). Gendered pressures: Divergent experiences linked to housework time among partnered men and women. Journal of Comparative Family Studies, 52(2), 147-179. https://doi.org/10.3138/jcfs-52-2-002

39. Miller, T. (2007). "Is this what motherhood is all about?": Weaving experiences and discourse through transition to first-time motherhood. Gender and Society, 21(3), 337-358. https://doi.org/ $10.1177 / 0891243207300561$

40. Moore, J. (2018). From "I'm never having children" to motherhood: A critical analysis of silence and voice in negotiations of childbearing face. Women's Studies in Communication, 41(1), 1-21. https://doi.org/10.1080/07491409.2017.1421282

41. Moras, A. (2017). "This should be my responsibility": Gender, guilt, privilege and paid domestic work. Gender Issues, 34, 44-66. https://doi.org/10.1007/s12147-016-9165-6

42. Newman, H. D., \& Henderson, A. C. (2014). The modern mystique: Institutional mediation of hegemonic motherhood. Sociological Inquiry, 84(3), 472-491. https://doi.org/10.1111/soin. 12037

43. O'Brien Hallstein, D. L. (2006). Conceiving intensive mothering: The Mommy Myth, Maternal Desire, and the lingering vestiges of matrophobia. Journal of the Association for Research on Mothering, 8(1-2), 96-108.

44. O'Brien Hallstein, D. L. (2008). Silences and choice: The legacies of White second wave feminism in the new professoriate. Women's Studies in Communication, 31(2), 143-150. https://doi. org/10.1080/07491409.2008.10162526

45. O'Brien Hallstein, D. L. (2017). Introduction to mothering rhetorics. Women's Studies in Communication, 4O(1), 1-10. https://doi.org/10.1080/07491409.2017.1280326

46. Olson, L. N., \& Simon, J. M. (2020). An ideological analysis of breastfeeding in contemporary America: Disciplining the maternal body. Lexington Books.

47. Organisation for Economic Co-operation and Development (OECD). (2019, June 3). Enabling women's economic empowerment: New approaches to unpaid care work in developing countries. https://www.oecd-ilibrary.org/sites/4d0229cd-en/index.html?itemId=/content/component/4d022 9cd-en

48. O'Reilly, A. (2016). Matricentric feminism: Theory, activism, and practice. Demeter Press.

49. O'Reilly, A. (2021). "Certainly not an equal-opportunity pandemic": COVID-19 and its impact on mothers' carework, health, and employment. In A. O'Reilly \& F. J. Green (Eds.), Mothers, mothering, and COVID-19: Dispatches from a pandemic (pp. 41-52). Demeter Press.

50. Pailhé, A., Solas, A., \& Stanfors, M. (2021). The great convergence: Gender and unpaid work in Europe and the United States. Population and Development Review, 47(1), 181-217.

51. Petts, R. J., Carlson, D. L., \& Pepin, J. R. (2021). A gendered pandemic: Childcare, homeschooling, and parents' employment during COVID-19. Gender, Work \& Organization, 28(S2), 515-534. https://doi.org/10.1111/gwao.12614

52. Rizzo, K. M., Schiffrin, H. H., \& Liss, M. (2013). Insight into the parenthood paradox: Mental health outcomes of intensive mothering. Journal of Child and Family Studies, 22(5), 614-620. https://doi.org/10.1007/s10826-012-9615-z

53. Rottenberg, C. (2018). The rise of neoliberal feminism. Oxford University Press.

54. Ruppanner, L., Tan, X., Carson, A., \& Ratcliff, S. (2021). Emotional and financial health during COVID-19: The role of housework, employment and childcare in Australia and the United States. Gender, Work \& Organization, 28(5), 1937-1955. https://doi.org/10.1111/gwao.12727

55. Sarker, M. R. (2021). Labor market and unpaid works implications of COVID-19 for Bangladeshi women. Gender, Work \& Organization, 28(S2), 597-604. https://doi.org/10.1111/gwao.12587

56. Shafer, K., Scheibling, C., \& Milkie, M. A. (2020). The division of domestic labor before and during the COVID-19 pandemic in Canada: Stagnation versus shifts in fathers' contributions. Canadian Review of Sociology, 57(4), 523-549. https://doi.org/10.1111/cars.12315

57. Silva, D., \& Miranda, L. (2021, February 6). About 275,000 women left workforce in January in "critical" pandemic trend, experts say. NBC News. https://www.nbcnews.com/news/us-news/about275-000-women-left-workforce-january-critical-pandemic-trend-n1256942 
58. Steimel, S. (2021). Communication privacy management and pregnancy loss in interpersonal workplace communication. Women's Studies in Communication, 44(3), 397-418. https://doi.org/10.1080/ 07491409.2020.1843579

59. Thornton, D. (2014). Transformations of the ideal mother: The story of mommy economicus and her amazing brain. Women's Studies in Communication, 37(3), 271-291. https://doi.org/10.1080/ 07491409.2014.944734

60. Tomlinson, J. (2008). Causes and consequences of the divergent working-time patterns of employed mothers in the UK and the US: Developing a comparative analysis. Gender Issues, 25, 246-266. https://doi.org/10.1007/s12147-008-9064-6

61. UN Women. (2019). Progress of the world's women 2019-2020: Families in a changing world, summary. https://www.unwomen.org/en/digital-library/progress-of-the-worlds-women

62. Waddell, N., Overall, N. C., Chang, V. T., \& Hammond, M. D. (2021). Gendered division of labor during a nationwide COVID-19 lockdown: Implications for relationship problems and satisfaction. Journal of Social and Personal Relationships, 38(6), 1759-1781. https://doi.org/10.1177/02654 07521996476

63. Whiley, L. A., Sayer, H., \& Juanchich, M. (2021). Motherhood and guilt in a pandemic: Negotiating the 'new' normal with a feminist identity. Gender, Work \& Organization, 28(S2), 612-619. https:// doi.org/10.1111/gwao.12613

64. Wolf, J. B. (2011). Is breast best? Taking on the breastfeeding experts and the new high stakes of motherhood. New York University Press.

65. Zamarro, G., \& Prados, M. J. (2021). Gender differences in couples' division of childcare, work and mental health during COVID-19. Review of Economics of the Household, 19, 11-40. https://doi.org/ $10.1007 / \mathrm{s} 11150-020-09534-7$

Publisher's Note Springer Nature remains neutral with regard to jurisdictional claims in published maps and institutional affiliations. 